\title{
Using probabilistic matching to improve opioid drug overdose surveillance, New Jersey
}

\author{
Bretta J. Jacquemin, Teresa Hamby, Stella Tsai \\ Center for Health Statistics, State of New Jersey, Department of Health, Trenton, New Jersey, United States
}

Objective

Link syndromic surveillance data for potential opioid-involved overdoses with hospital discharge data to assess positive predictive value of CDC Opioid Classifiers for conducting surveillance on acute drug overdoses.

\section{Introduction}

The opioid drug overdose crisis presents serious challenges to state-based public health surveillance programs, not the least of which is uncertainty in the detection of cases in existing data systems. New Jersey historically had slightly higher unintentional drug overdose death rates than the national average, but by 2001 dramatic increases in drug overdose deaths in states like West Virginia began to drive up the national rate (Figure 1). Although the rise in New Jersey's fatal overdose rates has mirrored the national rate since 1999, the rate has dramatically increased since 2011 - from 9.7 per 100,000 (868 deaths) to 21.9 per 100,000 in 2016 (1,931 deaths), an increase of $125 \%$ in five years [1].

The New Jersey Department of Health has been funded by the Centers for Disease Control and Prevention (CDC) to conduct surveillance of opioid-involved overdoses through the Enhanced Surveillance of Opioid-Involved Overdose in States (ESOOS) program, and to conduct syndromic surveillance through the National Syndromic Surveillance Program (NSSP); this has presented a collaboration opportunity for the Department's surveillance grantee programs to use existing resources to evaluate and refine New Jersey's drug overdose case definitions and develop new indicators to measure the burden of overdose throughout the state and to facilitate effective responses.

\section{Methods}

This work examined using probabilistic matching strategies to assess how accurately syndromic surveillance data identifies potential opioid-involved overdose patients by linking to hospital discharge records after subsequent treatment in an emergency department or inpatient setting for either a confirmed opioid- involved overdose or another condition(s).

New Jersey syndromic surveillance data from NSSP's ESSENCE system from December 2016 with either CDC's CCDD Classifiers "CDC Opioid Overdose V1" or "CDC Heroin Overdose V3" were selected for inclusion ("NJ ESSENCE data"). NJ ESSENCE data were restructured to produce one record per patient visit, with each record assigned one or more overdose classifiers; these records were then matched to the universe of acute care hospital discharge billing records from the New Jersey Hospital Discharge Data System ("UB data") from the same time period. Confirmed drug overdoses were flagged in the UB data by using the CDC's baseline ESOOS case definition, which searches all diagnosis fields for ICD-10-CM codes indicating an unintentional or undetermined intent drug overdose, an opioid overdose, or a heroin overdose. Optionally, there are suggested codes for mental and behavioral health conditions that indicate opioid abuse or dependence with intoxication (Table 1). Using SAS® software and PROC SQL, data were matched using a three-round "blocking" strategy based on facility identifier and admission date, and combinations of date of birth, sex, patient ZIP code, and age. Concordance of ESSENCE opioid overdose classifiers with indicator categories used by CDC's ESOOS was evaluated. Suspected opioid overdoses from NJ ESSENCE that matched to UB records for mental health conditions that were not also acute overdoses were reviewed.

\section{Results}

There were 253 records in NJ ESSENCE data with either "CDC Opioid Overdose V1" or "CDC Heroin Overdose V3" CCDD classifiers; restructuring the data resulted in 149 unique records of potential opioid overdoses. Of these, 106 (71\%) records from NJ ESSENCE were successfully matched to emergency department or inpatient records. Eighty (80) records (54\%), were matched in the first round using facility identifier and date of admission, date of birth, sex, and patient's home ZIP code. Of the 43 unmatched NJ ESSENCE records, 33 (77\%) were patients missing age and date of birth.

SDS Annual Conference Proceedings 2019. This is an Open Access article distributed under the terms of the Creative Commons AttributionNoncommercial 4.0 Unported License (http://creativecommons.org/licenses/by-nc/3.0/), permitting all non-commercial use, distribution, and reproduction in any medium, provided the original work is properly cited. 
Of the 106 matched records (Table 2):

- 74 opioid-involved overdoses in NJ ESSENCE matched to any drug overdose records in the UB data, for an overall PPV of $70 \%$.

- 69 opioid-involved overdoses in NJ ESSENCE matched to opioid-involved overdose records, for an opioid-involved PPV of $65 \%$.

- 54 heroin-involved overdoses in NJ ESSENCE matched to heroin-involved overdose records, for a heroin-involved PPV of $92 \%$.

- 32 matched records were NJ ESSENCE positive for opioids and UB negative, and 24 (75\%) were classified as potential heroin overdoses.

- 18 records had at least one mental and behavioral health condition code as part of the final discharge record.

- 3 were flagged with the mental and behavioral health conditions with opioid intoxication indicator.

Only one record appeared to be a possible false positive, with an NJ ESSENCE record indicating a "suspected heroin overdose or an overdose by unspecified drugs and of undetermined intent", but a discharge record indicated a primary diagnosis code of I46.9 (sudden cardiac arrest) and other systemic diagnoses but no poisoning or mental or behavioral health codes reported.

\section{Conclusions}

NJ ESSENCE data with CDC Opioid or Heroin Overdose Classifiers was able to correctly identify opioid-involved overdoses in matched records for patients experiencing an acute overdose better than 2 out of 3 times. For patients experiencing an acute heroin overdose the PPV was over $90 \%$. Cases with discordance in classification matched to records that may have been possible undetected drug intoxications or other mental and behavioral health conditions.

This work does not confirm that the CDC Opioid or Heroin Overdose Classifiers accurately capture all or even most drug overdoses treated in New Jersey hospitals reported to NSSP ESSENCE as of December 2016. A total of 1,461 discharges for acute drug overdoses were identified in UB data using the ESOOS case definition; 1,069 were treated and released from the emergency department, and 392 were admitted for further inpatient care. The 106 matched records only represent $7 \%$ of total overdose records identified in the UB data.

Further suggested work includes follow-up on possible data quality issues, pursuing a comprehensive project using all UBidentified overdoses matched to a broader selection of NJ ESSENCE data to examine what may be missed by the CDC's NSSP overdose classifiers, and using more recent data to test improvements made to the system since the original data pull.

\section{Acknowledgement}

NJ ESOOS is funded by CDC Grant Number 5 NU17CE924890; NJ NSSP is funded by CDC Grant Number 6 NU50OE000083.

\section{References}

1. Centers for Disease Control and Prevention, National Center for Injury Prevention and Control. Web-based Injury Statistics Query and Reporting System (WISQARS) [online]. (2005) [2018 Oct 1]. Available from URL: www.cdc.gov/injury/wisqars 


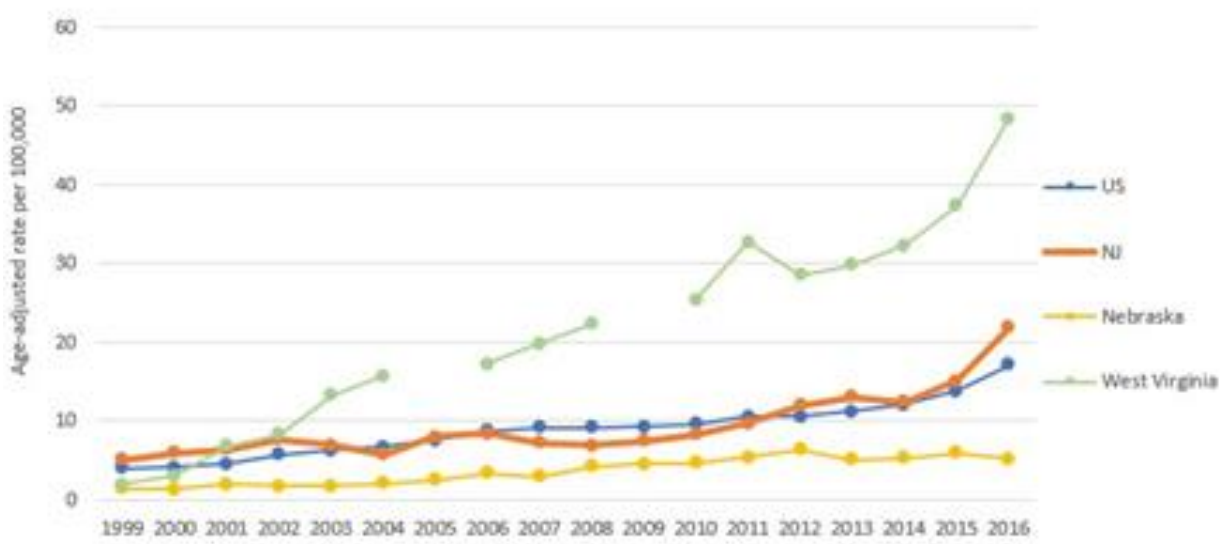

Figure 1. Unintentional Drug Overdose Deaths, 1999-2016

Source: CDC WISQARS, Unintentional Drug Overdose Deaths 1999-2016 (X40-X44). NOTE: NJ 2009 drug overdose death rate from New Jersey Department of Health NJSHAD; West Virginia and Nebraska were selected as comparison states because in 2016 they had the highest and lowest rates of drug overdose deaths, respectively.

Table 1. Case definitions for ESOOS and NSSP ESSENCE

\begin{tabular}{|c|c|}
\hline \multicolumn{1}{|c|}{$\begin{array}{c}\text { Surveillance Definition } \\
\text { ESOOS Unintentional or Undetermined Intent, any } \\
\text { drug overdose }\end{array}$} & Codes, Classifiers \\
\hline $\begin{array}{c}\text { TSOOS Unintentional or Undetermined Intent, any } \\
\text { opioid overdose }\end{array}$ & $\begin{array}{c}\text { T40.0-T40.4, T40.60, } \\
\text { T40.69 }\end{array}$ \\
\hline $\begin{array}{c}\text { ESOOS Unintentional or Undetermined Intent, heroin } \\
\text { overdose }\end{array}$ & T40.1 \\
\hline $\begin{array}{c}\text { ESOOS Optional Mental and Behavioral Health } \\
\text { Conditions, with Intoxication }\end{array}$ & F11.12, F11.22, F11.92 \\
NSSP & $\begin{array}{c}\text { "CDC Heroin Overdose } \\
\text { V3" }\end{array}$ \\
\hline
\end{tabular}

Table 2. Results 


\section{OJPHI}

ISDS 2019 Conference Abstracts

ISDS

INTERAATIONAL SOCIETY

\begin{tabular}{|c|c|c|c|c|c|c|c|}
\hline ESSENCE & Count & $\begin{array}{c}\text { No } \\
\text { Match }\end{array}$ & $\begin{array}{c}\text { Any Drug } \\
\text { Overdose }\end{array}$ & $\begin{array}{c}\text { Opioid } \\
\text { Overdose }\end{array}$ & $\begin{array}{c}\text { Heroin } \\
\text { Overdose }\end{array}$ & $\begin{array}{r}\text { Mental \& Behavioral } \\
\text { Health only }\end{array}$ & $\begin{array}{r}\text { No Drug or } \\
\text { MBH } \\
\text { codes }\end{array}$ \\
\hline $\begin{array}{c}\text { CDC Opioid } \\
\text { Overdose V1 }\end{array}$ & 45 & 19 & 18 & 13 & 5 & 3 & 5 \\
\hline $\begin{array}{c}\text { CDC Heroin } \\
\text { Overdose V3 }\end{array}$ & 104 & 24 & 56 & 56 & 54 & 3 & 21 \\
\hline $\begin{array}{c}\text { Any CDC } \\
\text { Classifier }\end{array}$ & 149 & 43 & 74 & 69 & 59 & 6 & 26 \\
\hline
\end{tabular}

